\title{
SURGICAL TREATMENT OF METACHRONOUS METASTASES IN DIFFERENT ORGANS FOLLOWING RADICAL NEPHRECTOMY
}

\author{
CARLOS M. N. DE JESUS, LUIZ A. CORRÊA, JOSÉ C. S. TRINDADE FILHO \\ Department of Urology, Botucatu School of Medicine, Paulista State University, \\ Botucatu, São Paulo, Brazil
}

\begin{abstract}
Renal clear cell carcinoma (RCCC) is a neoplasia resistant to radio and chemotherapy, with surgical treatment being the procedure that is recognized for its curative treatment. This case report demonstrates the success of an aggressive surgical treatment for consecutive and late metachronous metastases following radical nephrectomy.

Case report: Asymptomatic 50-year old man. During a routine examination, an incidental mass was found by renal ultrasonography. He underwent right radical nephrectomy due to RCCC in June 1992. During the follow-up metastases were evidenced in cerebellum on the seventh year, and in left lung and pancreas on the eighth year following the radical nephrectomy, with all of them successfully treated by surgical excision.

Comments: The surgical excision of consecutive and late metachronous metastases in different organs arising from RCCC is feasible, being a good therapeutic alternative in selected cases.
\end{abstract}

Key words: renal cell carcinoma; metastases; cerebellum; lung; pancreas; surgery Int Braz J Urol. 2003; 29: 238-240

\section{INTRODUCTION}

Renal clear cell carcinoma (RCCC) is a neoplasia resistant to radio and chemotherapy, with surgical ablation being the recognized method for its treatment with curative purposes. Radical nephrectomy is the gold standard for localized disease with tumors larger than $4 \mathrm{~cm}$, with a 5 -year survival ranging from 70 to $90 \%$ in theses cases (1). However, in metastatic disease there are few therapeutic alternatives, such as immunotherapy, with low success rates (2). This report presents a rare case with late and consecutive metachronous metastases of RCCC in different organs, successfully treated by surgical excision.

\section{CASE REPORT}

A male, 50-year old, Caucasian, asymptomatic patient, during routine examination was subjected to abdominal ultrasonography where an heterogeneous renal mass was found in the superior pole of the right kidney, measuring $7 \times 5 \mathrm{~cm}$. An abdominal computerized tomography was performed and detected a tumoral thrombus in the renal vein.

In June 1992, a right radical nephrectomy was performed, and the histopathological examination identified a grade II renal cell carcinoma in the superior pole, measuring $7.5 \times 5 \mathrm{~cm}$, with tumoral thrombus in the renal vein. Ipsilateral perirenal fat, capsule and suprarenal were free of neoplasia. Patient evolved post-operatively without intercurrences and was followed in an outpatient basis every 6 months with physical examination, chest RX, and abdominal tomography.

On the seventh year of follow-up, the patient suffered 2 episodes of syncope. A computerized tomography of the cranium was performed and detected a $3 \mathrm{~cm}$ tumoral mass in the left side of cerebellum. A 
craniotomy was indicated for exeresis of the mass with a histopathology compatible with RCCC.

One year after follow-up, 2 nodules of $1 \mathrm{~cm}$ were observed in the left lung (Figure-1). Left thoracotomy with wedge resection was indicated, evidencing grade II RCCC, compatible with previous histopathological examinations.

Finally, 6 months following thoracotomy, in an abdominal ultrasound there was the suspicion of a $2 \mathrm{~cm}$ hypoechogenic nodule in the body of pancreas. An abdominal computerized tomography was indicated, which confirmed the mass, and during the same procedure a guided puncture was performed that confirmed RCCC (Figure-2). It was then performed a body-tail pancreatectomy and splenectomy.

The patient is being followed for 2 years in an outpatient basis without evidences of neoplasic progression, presenting an excellent quality of life.

\section{COMMENTS}

Among the total cases of metastatic diseases due to RCCC, there is a subgroup where the metastatic disease arises as a single lesion in a particular organ following radical nephrectomy, which corresponds to 3 or $4 \%$ in large series of patients under

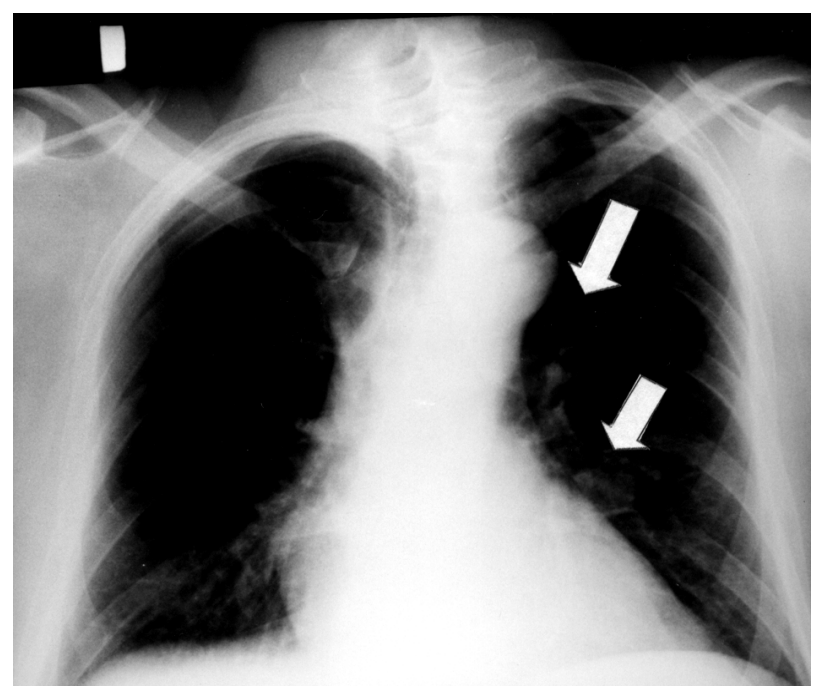

Figure 1 - Presence of renal clear cell carcinoma metastasis in left lung after the seventh year of follow-up (arrows).

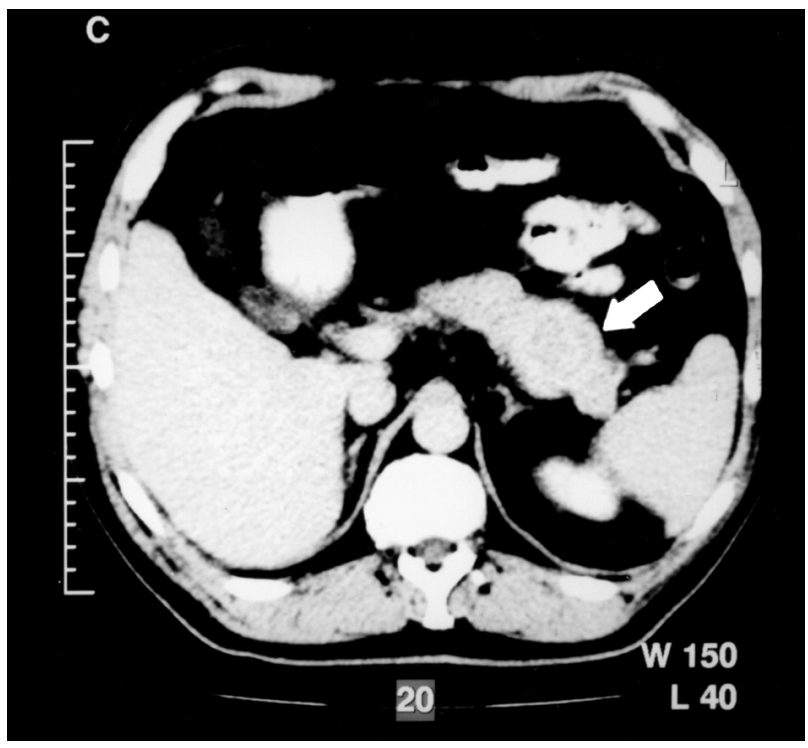

Figure 2 - Pancreatic metastasis of renal clear cell carcinoma. Note the pancreatic nodule between body and tail of pancreas (arrow).

such conditions. In such cases, the following are considered as good prognostic factors for treatment: 1) otherwise healthy patients, 2) age under 60 years, 3) single metastasis in lung, 4) period between nephrectomy and the occurrence of the lesion longer than 24 months $(2,3)$.

The successful aggressive treatment of consecutive metachronous metastases in different organs is a theme poorly addressed in the literature. Despite the controversial management and the short period of follow-up in this case relative to the exeresis of the last lesion (24 months) the patient presents an excellent outcome. We believe that in young, otherwise healthy patients who present a late recurrence with a single and organ-independent metastasis, the hypothesis of surgical treatment should be considered as a first line option for this selected subgroup.

\section{REFERENCES}

1. de Kernion JB, Ramming KP, Smith RB: The natural history of metastatic renal cell cancer: a computer analysis. J Urol. 1978; 120: 148-52.

2. Kozlowski JM: Management of distant solitary recur- 
rence in the patient with renal cancer. Urol Clin North Am. 1994; 21: 601-24.

3. Faure JP, Tuech JJ, RicherJP, Pessaux P, Arnaud JP,
Carretier M: Pancreatic metastasis of renal cell carcinoma: presentation, treatment and survival. J Urol. 2001; 165: 20-2.

Received: December 27, 2002

Accepted after revision: March 25, 2003

\author{
$\overline{\text { Correspondence address: }}$ \\ Dr. Carlos M. N. de Jesus \\ Departamento de Urologia \\ Faculdade de Medicina de Botucatu \\ Distrito de Rubião Júnior \\ Botucatu, São Paulo, 18618-970, Brazil \\ Fax.: + 5514 6802-6271 \\ E-mail: marcio@ fmb.unesp.br
}

